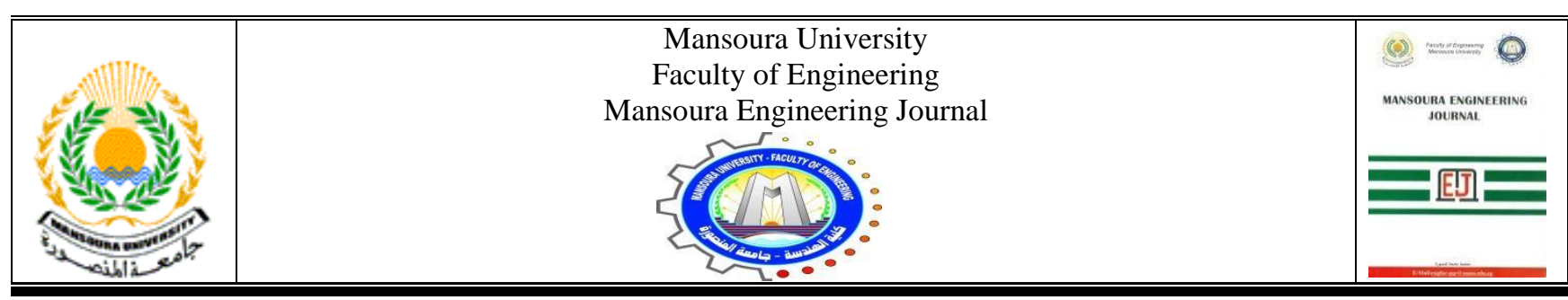

\title{
Effect of Main Channel Bed Roughness on the Branch Channel Discharge
}

\author{
Tarek Sayed
}

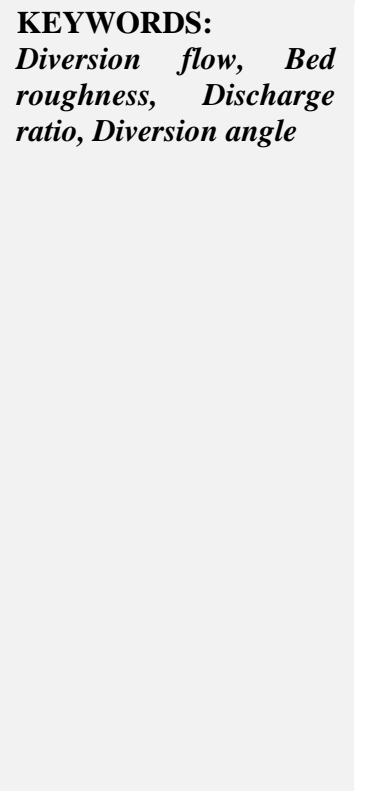

\begin{abstract}
In light of the current complex water situation in Egypt, scientists and researchers have to develop alternative plans to provide new quantities of water by paying attention to the constructions and tools that are used in distributing and controlling the flow in open channels. One of the most critical parameters in the analysis of diversion channel flow is the discharge ratio (Qr). It is the primary goal of this research to investigate the effect of changing the bed roughness of the main channel on the discharge of the branch channel $(\mathrm{Qb})$. The bed roughness of the branch channel was kept constant (nb $=0.01$ ), while for the main channel bed roughness was changed to five values $(\mathrm{nm}=0.01,0.016,0.023,0.033$, and 0.04$)$. The diversion angle of the branch channel was taken as $\left(45^{\circ}\right)$, which gave a maximum $(\mathrm{Qr})$ as recommended by some researchers. A discharge range from 4.88 to $17.14 \mathrm{~L} / \mathrm{sec}$ was used, and 35 runs were conducted. From the analysis of the laboratory data, it was found that the discharge ratio $(\mathrm{Qr})$ decreases as the total discharge through the main channel increases. While it increases with the increase of bed roughness ratios (nr). Moreover, at the bed roughness ratios (nr) ranged from 2.20 to 3.0, the difference in the discharge ratio $(\mathrm{Qr})$ is no significant, for all discharge values passing through the main channel. Thus, maintaining a constant flow rate for the branched channel is considered one of the most essential factors in designing these channels, as it is vital in distributing water shares as percentages and in a consistent manner.
\end{abstract}

\section{I.INTRODUCTION}

$\mathrm{N}$ owadays, the most dangerous problem facing Egypt is the limitation and shortage of available water from the River Nile. Therefore, improving the efficiency of distributing, transporting, and controlling of the available limited quantity of water is one of the most effective parameters in water saving, the researchers' attention must orient towards the constructions and tools that used in distributing and controlling the flow in open channels, [1]. Studying the flow in the branching channels still garners the attention of water resources engineering researchers, as it commonly exists in many water engineering-related projects, [2]. The design of the irrigation projects depends on the hydraulic

Received: (10 October, 2020) - Revised: (16 February, 2021) Accepted: (22 February, 2021) design for them, so the water resources engineering designers must take into consideration several factors that affecting in the design of the branching channels such as the primary channel flow, riverbed mechanics, and changing the bed form, especially in the junction region, [3]. These changes have to lead to many problems, such as changes in the main channel slope due to erosion and sedimentation in the main channel as well as on the branch channel. Many researchers and investigators have carried out numerous studies and experiments for reaching the optimum angle of diversion at $45^{\circ}$ which give a maximum $\left(\mathrm{Q}_{\mathrm{r}}\right)$ such as given by Masjedi and Taeedi [4], Pirestani et al. [5], Tarek Sayed [6], and Al Omari and Khaleel [7], a minimum amount of diverted sediment as presented by Pirestani et al. [5] and Dehghani et al. [8], and minimum separation zone size of the intake channel _as highlighted

Corresponding Author: Tarek Sayed, Assistant Professor, Department of Civil Engineering, Assiut University, Assiut, Egypt. Email: tareksayed1986@aun.edu.eg; tareksayed1986@gmail.com 
by Keshavarzi and Habibi [9], Ramamurthy et al. [10] and Herrero_[11]. Moreover, they have investigated the distribution of velocity components experimentally in the branching channel (e.g., Ramamurthy et al. [10], Bagheri and Heidarpour [12]) and numerically (e.g., Shamloo and Pirzadeh [13, and 14]) Also, they have introduced equations to describe $\left(\mathrm{Q}_{\mathrm{r}}\right)$ in the branching channel system such as given by Ramamurthy and Satish [15], Ramamurthy et al. [16], and Hsu et al. [17].

To the best of the author knowledge, there are limited references, such as given by Neary and Odgaard [18], Li and Zeng [19], and Khaleel et al. [20], for investigating the effects of the roughness of the bed on the flow behavior in the branching channel system. This paper is concerned with a laboratory study to investigate the effect of changing the bed roughness of the main channel on the discharge ratio $\left(Q_{r}\right)$. Also, the main goal of this study to introduce simple, practical equations for illustrating the relation between the discharge ratio $\left(\mathrm{Q}_{\mathrm{r}}\right)$ and the ratio of bed roughness of the main channel to the bed roughness of the branch channel $\left(\mathrm{n}_{\mathrm{r}}\right)$.

\section{II.MATERIAL AND METHODS}

Experiments have been conducted in a re-circulation, rectangular open tilting flume at the irrigation and hydraulics laboratory in the Civil Engineering Department at Assiut University, Egypt. A laboratory channel consists of two parts, the main channel and a branch channel. A schematic layout of the experimental channel was shown in the following Fig. (1). The main channel has $13.50 \mathrm{~m}$. long, $30 \mathrm{~cm}$ wide and $30 \mathrm{~cm}$ in depth. The division corner to the branch channel has sharped edged and located $7.0 \mathrm{~m}$ downstream from the main channel inlet. The branch channel was $3.0 \mathrm{~m}$. long, $30 \mathrm{~cm}$ wide and $30 \mathrm{~cm}$ depth. The total discharge was delivered by a pump and measured using a calibrated orifice meter with a manometer. The discharges from the main and branch channels were measured using two sharp-edged weirs, $30 \mathrm{~cm}$ wide and 10 $\mathrm{cm}$ depth, and were installed at the end of the channels. These weirs were calibrated with the volumetric method; the calibrated discharge equation of the weir is:

$Q_{w}=0.512 H^{1.5}$

Where $\left(\mathrm{Q}_{\mathrm{w}}\right)$ is the discharge in $\mathrm{L} / \mathrm{sec}$., and $(\mathrm{H})$ is the head of water above the weir in $\mathrm{cm}$.

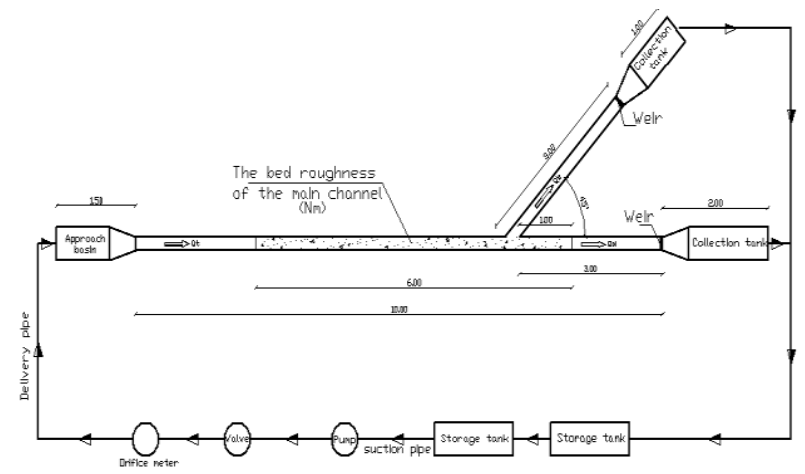

Fig. (1): Schematic sketch of the experimental flume.

Experimental Approach

The downstream flow was in subcritical condition in all experiments. The discharge in all observations varied between 4.88 and $17.14 \mathrm{~L} / \mathrm{sec}$. For each run, the discharge in the branch channel, the discharge downstream of the main channel, the total discharge were measured, and the discharge ratio (Qr) was calculated.

To make the main channel bed roughness, the main channel bed was furnished with gravel particles which its diameter at $90 \%$ passing $\left(d_{90}\right)$ is $11.7 \mathrm{~mm}$. The mechanism of that is the gravel was glued to plates, which glued to the main channel bed by Silicone. To study the effect of changing the main channel bed roughness, the gravel was glued to the plates with four different densities to obtain four different values of the Manning coefficient $\left(\mathrm{n}_{\mathrm{m}}\right.$ $=0.016,0.023,0.033,0.04)$ as shown in the following Photo (1). In addition to the case, the main channel and the branch channel have the same bed roughness as reference. The rough bed starts $2.0 \mathrm{~m}$ from the main channel inlet and extends $6.0 \mathrm{~m}$ long. Fig (2) shows the particle size distribution for this type of gravel. Moreover, the value of the Manning coefficient for the branch channel $\left(\mathrm{n}_{\mathrm{b}}\right)$ equals to 0.01 .

The laboratory experiments were performed using five different values for the bed roughness ratio $\left(\mathrm{n}_{\mathrm{r}}\right)$, which was used to describe the ratio of main channel roughness to the roughness of the branch channel bed $\left(\mathrm{n}_{\mathrm{r}}=1.0,1.6,2.3,3.3\right.$ and 4.0). For each bed roughness ratio, seven different discharges were passed through the main channel. All experiments were carried out with a steady flow condition. The flow downstream, the main and branch channel, was free and subcritical. The total number of runs was 35 .

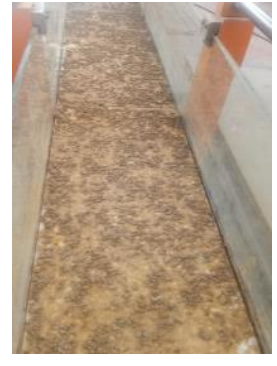

(a) $\mathrm{n}_{\mathrm{m}}=0.016$

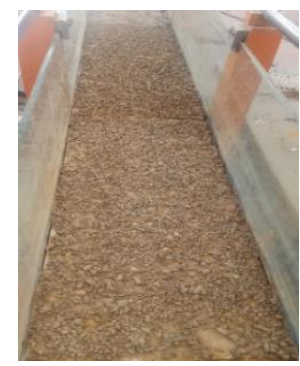

(c) $\mathrm{n}_{\mathrm{m}}=0.033$

Photo (1): Different densities of the gravel, which glued to the plates to give different values of the Manning coefficient

\section{Experimental Procedure}

To perform any case of experiments, runs were started by connecting the branch channel to the main channel with 
the diversion angle $\left(\alpha=45^{\circ}\right)$. The storage, feeding tank was filled with water. The pump was triggered by a switch then the intake valve of the feeding pipeline was opened slowly to give a definite value of discharge by adjusting both the intake valve and the orifice manometer reading. As a result of installing a sharp-edged weir at the end of the main and the branch channel to measure the discharge, the downstream flow was subcritical. After a period of about 10 to 15 minutes, the flow was steady. The discharges from the main and branch channels were measured. Afterward, the branching flow ratios were calculated. The results of the experimental work were listed, as shown in the following Table (1). It is observed from this table, column (5), increasing the value of total discharge $\left(Q_{t}\right)$ increases the discharge in the branched canal $\left(\mathrm{Q}_{\mathrm{b}}\right)$ and decreases value of relative discharge $\left(\mathrm{Q}_{\mathrm{r}}\right)$ for all values of Manning coefficient $\left(\mathrm{n}_{\mathrm{b}}\right)$ of the main canal. Increase the percentage value of $Q_{r}$ with increasing value of discharge and the roughness ratio in comparison with $\mathrm{n}_{\mathrm{r}}$ equal to1.0. Also, the increase in $\mathrm{Q}_{\mathrm{r}}$ increases with the increasing value of discharge in the main canal for $\mathrm{n}_{\mathrm{r}}$ equal to 1.6 and 2.3 but for $\mathrm{n}_{\mathrm{r}}$ equal to 3.3 and 4.0 the percentage may decrease with discharge of the main canal.

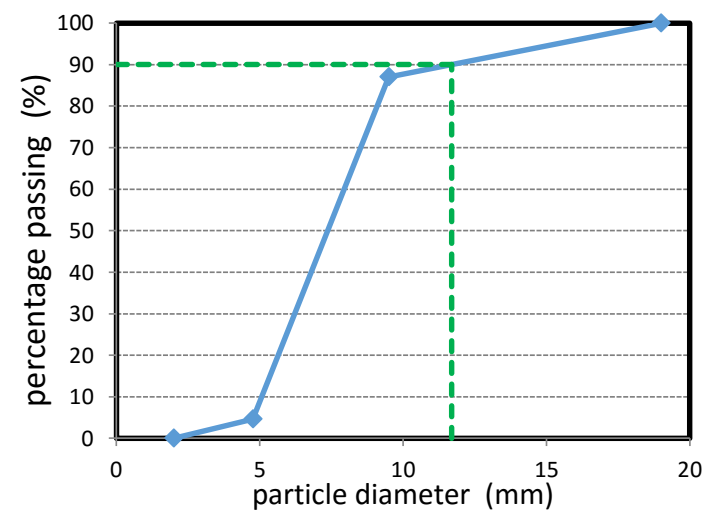

Fig. (2): Gradation curve of the used gravel

\section{III.RESULTS AND DISCUSSION}

Branched channel flow refers to the diversion of some part of the water from the main channel. Usually, the discharge ratio $\left(\mathrm{Q}_{\mathrm{r}}\right)$ is used to describe the branching channel flow. Diversion of some of the total discharge to the branch channel effects the main channel flow and changing the bed form, especially in the branching region [3]. Therefore, in this study, the analysis of laboratory data has been performed to reach the value of the bed roughness ratio $\left(n_{r}\right)$, which gives a constant flow rate for the branched channel for all discharges passing in the main channel. Also, one of the main goals of this research is to obtain simple, practical equations to help the researchers of the water resources in the determination of the percentage of discharge diverted to the branch channel.

Experimental results were expressed in dimensionless forms and represented in tables and graphically to show the effect of changing the bed roughness of the main channel on the discharge ratio $\left(\mathrm{Q}_{\mathrm{r}}\right)$. The bed roughness ratio of the main channel to the branch channel was changed five times $(1.0,1.6,2.3,3.3$, and 4.0). The branch angle was taken as $\left(45^{\circ}\right)$, which gave a maximum $\left(\mathrm{Q}_{\mathrm{r}}\right)$ as recommended by Masjedi and Taeedi [4], Pirestani et al. [5], Tarek Sayed [6].

\section{Relationship between the Discharge Ratio $\left(Q_{r}\right)$ and the} Total discharge $\left(Q_{t}\right)$

The following Fig. (3) was plotted for the relation between the discharge ratio $\left(\mathrm{Q}_{\mathrm{r}}\right)$ and the total discharge $\left(Q_{t}\right)$ for all understudy bed roughness ratios $\left(n_{r}\right)$. From this figure, it is clear that the discharge ratio $\left(\mathrm{Q}_{\mathrm{r}}\right)$ increases with the increase of bed roughness ratio $\left(\mathrm{n}_{\mathrm{r}}\right)$. Moreover, there is a robust linear relationship between the discharge ratio $\left(\mathrm{Q}_{\mathrm{r}}\right)$ and the total discharge $\left(\mathrm{Q}_{\mathrm{t}}\right)$, this relationship is an inverse relationship for all understudy bed roughness ratio $\left(n_{r}\right)$.

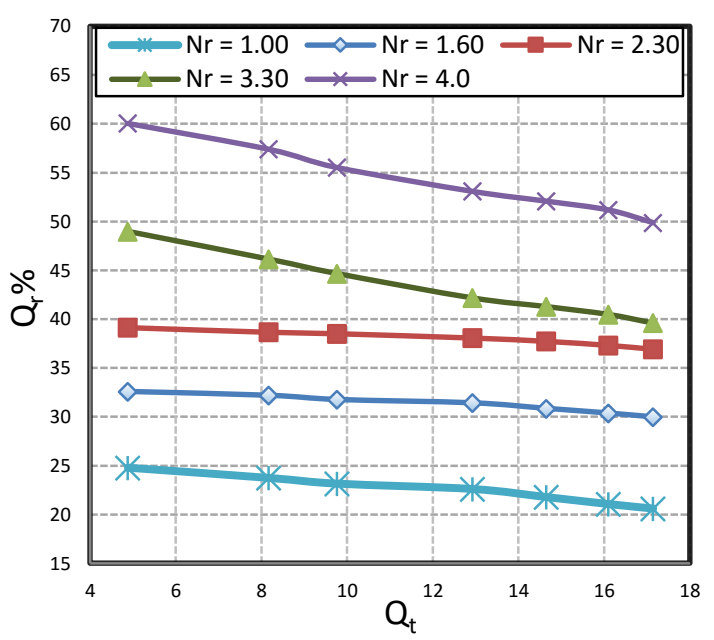

Fig. (3): Relationship between the Discharge Ratio (Qr) and the total discharge $(\mathrm{Qt})$ for different bed roughness ratios $(\mathrm{nr})$

Also, from this figure, it is noticed that for $\left(\mathrm{n}_{\mathrm{r}}=1.60\right.$, $2.30)$, the rate of decrease in the discharge ratio $\left(Q_{r}\right)$ is very low with the increase in the total discharge $\left(\mathrm{Q}_{\mathrm{t}}\right)$. While the rate of decrease was high at $\left(n_{r}=3.30,4.0\right)$. This may be due to the increase of bed roughness of the main channel $\left(n_{m}\right)$ which leads to a decrease in the velocity of the flow, and therefore the reduction in the main channel discharge, leads to the ease of diversion significant amount of water into the branch channel.

For the comparison purpose, the last column in Table (1) has been constructed to present the percentage of increase in the discharge ratio $\left(\mathrm{Q}_{\mathrm{r}}\right)$ as a result of using different values of bed roughness ratios $\left(n_{r}\right)$. The calculations showed that, using bed roughness ratio $\left(\mathrm{n}_{\mathrm{r}}\right)=$ $(1.60,2.30,3.30,4.0)$ can increase the discharge ratio $\left(\mathrm{Q}_{\mathrm{r}}\right)$ percentage from 31.42 to 45.60 , from 57.88 to 79.36 , from 86.64 to 97.54 , and from 134.91 to 143.13 respectively more than that obtained in the case of bed roughness $\left(n_{r}\right)$ equal to 1.0. This is so good in the design of the branch channel, as it ensures controlling the quantities of water diverted to the branch channel without establishing more water constructions. 
TABLE (1)

EXPERIMENTAL MEASUREMENTS AND CALCULATED $N_{R}$ AND $Q_{R}$

\begin{tabular}{|c|c|c|c|c|c|c|c|c|}
\hline Run & $\begin{array}{c}Q_{t} \\
(l / s)\end{array}$ & $\begin{array}{c}Q_{d} \\
(l / s)\end{array}$ & $\begin{array}{c}Q_{b} \\
(l / s)\end{array}$ & $\begin{array}{c}\boldsymbol{Q}_{\boldsymbol{r}} \\
\left(\mathrm{Q}_{\mathrm{b}} / \mathrm{Q}_{\mathrm{t}}\right) \\
* \mathbf{1 0 0}\end{array}$ & $n_{m}$ & $n_{b}$ & $\begin{array}{c}\boldsymbol{n}_{\boldsymbol{r}} \\
\left(\mathrm{n}_{\mathrm{m}} / \mathrm{n}_{\mathrm{b}}\right)\end{array}$ & $\begin{array}{c}\text { Percentage increase of the }\left(Q_{r}\right) \text { for } \\
\text { the different values of }\left(n_{r}\right) \text { compared } \\
\text { with the case of }\left(n_{r}=1.0\right)\end{array}$ \\
\hline 1 & 4.88 & 3.67 & 1.21 & 24.79 & 0.01 & 0.01 & 1.00 & 0.00 \\
\hline 2 & 8.17 & 6.23 & 1.94 & 23.74 & 0.01 & 0.01 & 1.00 & 0.00 \\
\hline 3 & 9.76 & 7.50 & 2.26 & 23.15 & 0.01 & 0.01 & 1.00 & 0.00 \\
\hline 4 & 12.92 & 10.00 & 2.92 & 22.60 & 0.01 & 0.01 & 1.00 & 0.00 \\
\hline 5 & 14.65 & 11.46 & 3.19 & 21.77 & 0.01 & 0.01 & 1.00 & 0.00 \\
\hline 6 & 16.10 & 12.71 & 3.39 & 21.05 & 0.01 & 0.01 & 1.00 & 0.00 \\
\hline 7 & 17.14 & 13.61 & 3.53 & 20.59 & 0.01 & 0.01 & 1.00 & 0.00 \\
\hline 8 & 4.88 & 3.29 & 1.59 & 32.58 & 0.016 & 0.01 & 1.60 & 31.42 \\
\hline 9 & 8.17 & 5.54 & 2.63 & 32.19 & 0.016 & 0.01 & 1.60 & 35.59 \\
\hline 10 & 9.76 & 6.66 & 3.10 & 31.76 & 0.016 & 0.01 & 1.60 & 37.19 \\
\hline 11 & 12.92 & 8.86 & 4.06 & 31.42 & 0.016 & 0.01 & 1.60 & 39.03 \\
\hline 12 & 14.65 & 10.13 & 4.52 & 30.85 & 0.016 & 0.01 & 1.60 & 41.71 \\
\hline 13 & 16.10 & 11.21 & 4.89 & 30.37 & 0.016 & 0.01 & 1.60 & 44.27 \\
\hline 14 & 17.14 & 12.00 & 5.14 & 29.98 & 0.016 & 0.01 & 1.60 & 45.60 \\
\hline 15 & 4.88 & 2.97 & 1.91 & 39.14 & 0.023 & 0.01 & 2.30 & 57.88 \\
\hline 16 & 8.17 & 5.01 & 3.16 & 38.67 & 0.023 & 0.01 & 2.30 & 62.89 \\
\hline 17 & 9.76 & 6.00 & 3.76 & 38.52 & 0.023 & 0.01 & 2.30 & 66.39 \\
\hline 18 & 12.92 & 8.00 & 4.92 & 38.08 & 0.023 & 0.01 & 2.30 & 68.49 \\
\hline 19 & 14.65 & 9.12 & 5.53 & 37.74 & 0.023 & 0.01 & 2.30 & 73.36 \\
\hline 20 & 16.10 & 10.09 & 6.01 & 37.33 & 0.023 & 0.01 & 2.30 & 77.34 \\
\hline 21 & 17.14 & 10.81 & 6.33 & 36.93 & 0.023 & 0.01 & 2.30 & 79.36 \\
\hline 22 & 4.88 & 2.49 & 2.39 & 48.97 & 0.033 & 0.01 & 3.30 & 97.54 \\
\hline 23 & 8.17 & 4.40 & 3.77 & 46.14 & 0.033 & 0.01 & 3.30 & 94.36 \\
\hline 24 & 9.76 & 5.40 & 4.36 & 44.67 & 0.033 & 0.01 & 3.30 & 92.96 \\
\hline 25 & 12.92 & 7.47 & 5.45 & 42.18 & 0.033 & 0.01 & 3.30 & 86.64 \\
\hline 26 & 14.65 & 8.60 & 6.05 & 41.29 & 0.033 & 0.01 & 3.30 & 89.66 \\
\hline 27 & 16.10 & 9.58 & 6.52 & 40.49 & 0.033 & 0.01 & 3.30 & 92.35 \\
\hline 28 & 17.14 & 10.35 & 6.79 & 39.61 & 0.033 & 0.01 & 3.30 & 92.37 \\
\hline 29 & 4.88 & 1.95 & 2.93 & 60.05 & 0.040 & 0.01 & 4.0 & 142.23 \\
\hline 30 & 8.17 & 3.48 & 4.69 & 57.40 & 0.040 & 0.01 & 4.0 & 141.78 \\
\hline 31 & 9.76 & 4.34 & 5.42 & 55.53 & 0.040 & 0.01 & 4.0 & 139.87 \\
\hline 32 & 12.92 & 6.06 & 6.86 & 53.09 & 0.040 & 0.01 & 4.0 & 134.91 \\
\hline 33 & 14.65 & 7.02 & 7.63 & 52.08 & 0.040 & 0.01 & 4.0 & 139.23 \\
\hline 34 & 16.10 & 7.86 & 8.24 & 51.18 & 0.040 & 0.01 & 4.0 & 143.13 \\
\hline 35 & 17.14 & 8.59 & 8.55 & 49.88 & 0.040 & 0.01 & 4.0 & 142.25 \\
\hline
\end{tabular}

Based on the experimental data and using the simple and multiple linear regression analysis, the best equation for predicting the discharge ratio $\left(\mathrm{Q}_{\mathrm{r}}\right)$ for all understudy bed roughness ratios $\left(n_{r}\right)$ c can be written in the following form:

$Q_{r}=a_{1}\left(Q_{t}\right)+a_{2}$

The values of $\mathrm{R}^{2}$ ranged from 0.958 to 0.994 . The coefficients $\left(\mathrm{a}_{1}\right.$, and $\left.\mathrm{a}_{2}\right)$ are constants depending on the bed roughness ratio; their values are given in the following Table (2).

TABLE (2)

VALUES OF COEFFICIENTS ( $\mathrm{A}_{1}$, AND $\mathrm{A}_{2}$ ) IN EQ. (2)

\begin{tabular}{c||c||c}
$\boldsymbol{n}_{\boldsymbol{r}}$ & $\boldsymbol{a}_{\mathbf{1}}$ & $\boldsymbol{a}_{\boldsymbol{2}}$ \\
\hline $\mathbf{1 . 0}$ & -0.3302 & 26.472 \\
\hline $\mathbf{1 . 6 0}$ & -0.2077 & 33.789 \\
\hline $\mathbf{2 . 3 0}$ & -0.1703 & 40.093 \\
\hline $\mathbf{3 . 3 0}$ & -0.7504 & 52.30 \\
\hline $\mathbf{4 . 0}$ & -0.8079 & 63.824
\end{tabular}

It is noticed from this table that increasing the value of relative roughness $\left(n_{r}\right)$ decreases the value of $a_{1}$ and increases the value of $\mathrm{a}_{2}$.

\section{Relationship between the Discharge Ratio $\left(Q_{r}\right)$ and the Bed Roughness Ratio $\left(n_{r}\right)$}

To illustrate the effect of changing the bed roughness of the main channel on the discharge ratio $\left(\mathrm{Q}_{\mathrm{r}}\right)$, the relationship between the discharge ratio $\left(\mathrm{Q}_{\mathrm{r}}\right)$ and the bed roughness ratios $\left(\mathrm{n}_{\mathrm{r}}\right)$, at different discharges, was plotted as shown in the following Fig. (4). From this figure, it is observed that the discharge ratio $\left(\mathrm{Q}_{\mathrm{r}}\right)$ increases with the increase of bed roughness ratio $\left(\mathrm{n}_{\mathrm{r}}\right)$. Moreover, for the same value of the bed roughness ratio $\left(\mathrm{n}_{\mathrm{r}}\right)$, the discharge ratio $\left(\mathrm{Q}_{\mathrm{r}}\right)$ decreases by increasing value of the total discharge $\left(Q_{t}\right)$ passing through the main channel. Furthermore, at the bed roughness ratio $\left(\mathrm{n}_{\mathrm{r}}\right)$ varies between 2.20 and 3.0, the discharge ratio $\left(\mathrm{Q}_{\mathrm{r}}\right)$ may be constant, for high values of discharges passing through the main 
channel. While at the bed roughness ratio $\left(\mathrm{n}_{\mathrm{r}}\right)$ is bigger than 3.0, the discharge ratio $\left(\mathrm{Q}_{\mathrm{r}}\right)$ increases by a high rate for all understudy values of discharge passing through the main channel.

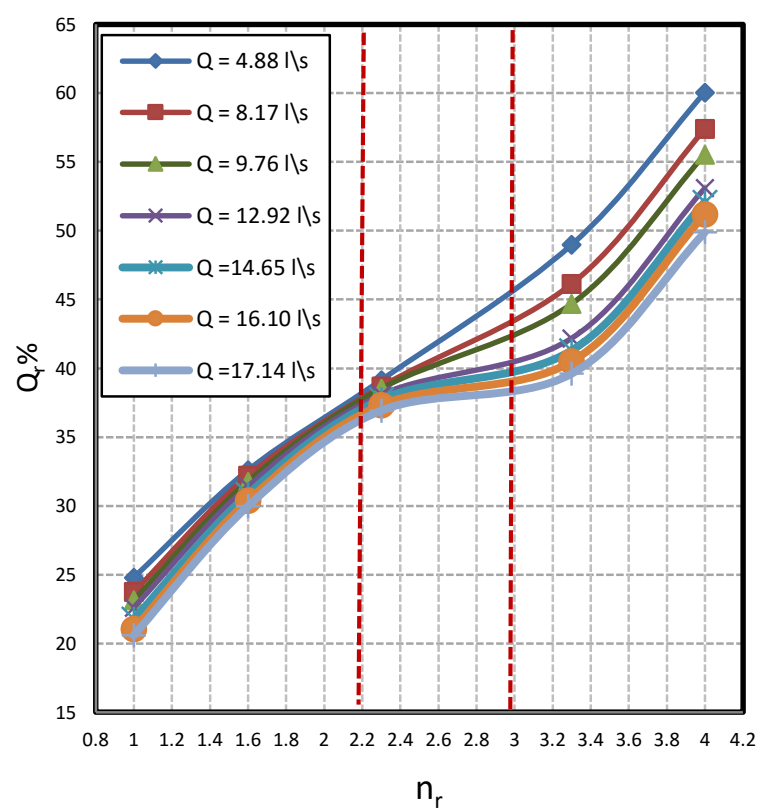

Fig. (4): Relationship between the discharge ratio $\left(\mathrm{Q}_{\mathrm{r}}\right)$ and the bed roughness ratios $\left(\mathrm{n}_{\mathrm{r}}\right)$ for different values of discharge $\left(\mathrm{Q}_{\mathrm{t}}\right)$

It is maintaining a constant flow rate for the branching channel considered one of the most critical factors in designing the branching channels, as it is vital in distributing water shares as percentages and in a consistent manner for all branching channels.

Based on the experimental data and using the simple and multiple linear regression analysis, the best equation for predicting the discharge ratio $\left(\mathrm{Q}_{\mathrm{r}}\right)$ as a function of the bed roughness ratio $\left(\mathrm{n}_{\mathrm{r}}\right)$ for all understudy discharges ، can be written in the following form:

$Q_{r}=a_{3}\left(n_{r}\right)^{a_{4}}$

The values of $\mathrm{R}^{2}$ ranged from 0.9626 to 0.9884 . The coefficients $\left(\mathrm{a}_{3}\right.$, and $\left.\mathrm{a}_{4}\right)$ are constants depending on the discharge value, their values are given in Table (3). It is noticed from this table that increasing the value of main channel discharge decreases both values of $\mathrm{a}_{3}$, and $\mathrm{a}_{4}$

TABLE (3)

VALUES OF COEFFICIENTS ( $\mathrm{A}_{3}$, AND $\mathrm{A}_{4}$ ) IN EQ. (3)

\begin{tabular}{c||c||c}
$\mathrm{Q}_{\mathrm{t}}(\mathrm{L} / \mathrm{s})$ & $\boldsymbol{a}_{\mathbf{3}}$ & $\boldsymbol{a}_{4}$ \\
\hline 4.88 & 24.350 & 0.6142 \\
\hline 8.17 & 23.758 & 0.6016 \\
\hline 9.76 & 23.399 & 0.5933 \\
\hline 12.92 & 23.143 & 0.5693 \\
\hline 14.65 & 22.470 & 0.5802 \\
\hline 16.10 & 21.880 & 0.5894 \\
\hline 17.14 & 21.533 & 0.5859
\end{tabular}

For predicting an equation to obtain the discharge ratio $\left(\mathrm{Q}_{\mathrm{r}}\right)$, which describes the branching flow for the optimum angle of branching $\left(45^{\circ}\right)$, as a function of the total discharge $\left(\mathrm{Q}_{\mathrm{t}}\right)$ of the main channel and the bed roughness ratio $\left(\mathrm{n}_{\mathrm{r}}\right)$. The simple and multiple linear regression analysis was used, and the equation as derived from the statistical program SPSS by using two-thirds of the values of the measured variables can be written in the following form:

$Q_{r}=-0.470\left(Q_{t}\right)+9.684\left(n_{r}\right)+20.129$

The value of $\mathrm{R}^{2}$ equal to 0.965 . The remaining third of the values of the variables were used for verifying the Eq. (4). Fig. (5) shows a comparison between the measured discharge ratio $\left(\mathrm{Q}_{\mathrm{r}}\right)$ and the calculated one using the developed Eq. (4). It can be noticed that the predicted data have a good agreement with the measured ones.

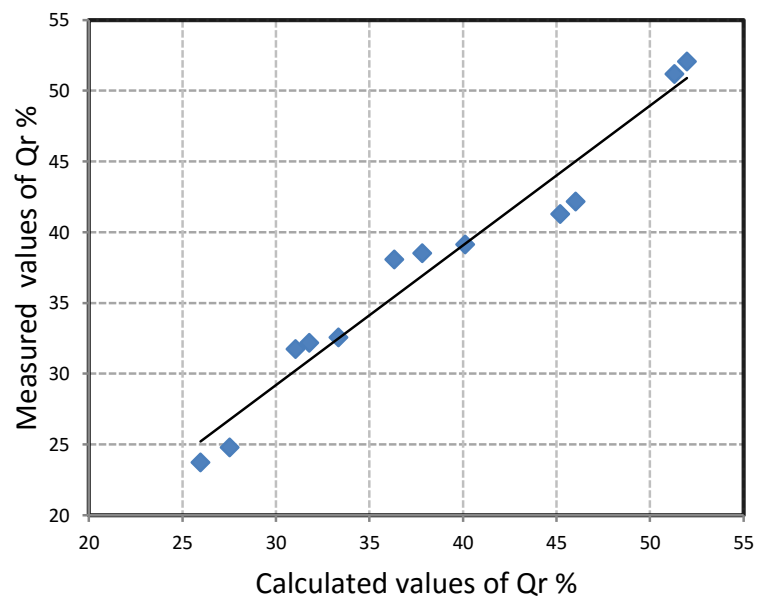

Fig. (5): Comparison between measured and calculated values of discharge ratio using Eq. (4).

\section{IV.CONCLUSIONS}

Laboratory experiments have been conducted to study the effect of the bed roughness of the main channel on the branch channel discharge $\left(\mathrm{Q}_{\mathrm{b}}\right)$. Through this study and its experimental results, the following main conclusions can be drawn:

(1) For all studied bed roughness ratio, the branching flow ratio $\left(\mathrm{Q}_{\mathrm{r}}\right)$ decreases as the total discharge through the main channel increases.

(2) For all studied cases, as the bed roughness ratio $\left(n_{r}\right)$ increase, the discharge ratio $\left(\mathrm{Q}_{\mathrm{r}}\right)$ increases.

(3) Finally, according to the obtained results, it is strongly recommended using the bed roughness ratio $\left(\mathrm{n}_{\mathrm{r}}\right)$ varies between 2.20 and 3.0 to obtain a constant flow rate for the branched channel, which considered one of the most essential factors in designing these channels, as it is vital in distributing water shares as percentages and in a consistent manner. 


\section{NOTATION}

The following symbols are used in this paper:

$a_{1}, a_{2}, a_{3}, a_{4}$

$$
\begin{gathered}
\mathrm{n}_{\mathrm{b}} \\
\mathrm{n}_{\mathrm{m}} \\
\mathrm{n}_{\mathrm{r}} \\
\mathrm{Q}_{\mathrm{b}} \\
\mathrm{Q}_{\mathrm{d}} \\
\mathrm{Q}_{\mathrm{r}} \\
\mathrm{Q}_{\mathrm{t}} \\
\mathrm{R}^{2}
\end{gathered}
$$

Coefficients depend on the bed roughness ratio;

The bed roughness of the branch channel;

The bed roughness of the main channel;

The bed roughness ratio;

The discharge of the branch channel; The downstream discharge of main channel;

The discharge ratio;

The total discharge;

Determination coefficient; and

Branching angle.

\section{REFERENCES}

[1] [1] Ashour M. A., Tarek Sayed, and Salah, E. (2014). A new water energy dissipater for efficient energy dissipation and enriching the flow with dissolved oxygen content. Limnol. Rev. 14(1): 3-11.

[2] [2] Lama, S. K., Kuroki, M., and Hasegawa, K. (2002). Study of flow bifurcation at the $30^{\circ}$ open channel junction when the width ratio of branch channel to main channel is large. Annual Journal of Hydraulic Engineering, JSCE, Vol.46, February, 583-588.

[3] [3] Yonesi, H. A., Omid, M. H., and Haghiabi, A. H. (2008). A study of the effects of the longitudinal arrangement sediment behavior near intake structures. Journal of Hydraulic Research, 46(6), 814-819

[4] [4] Masjedi, A., and Taeedi, A. (2011). Experimental investigations of effect intake angle on discharge in lateral intakes in 180-degree bend. World Applied Sciences Journal, 15(10), 1442-1444.

[5] [5] Pirestani, M. R., Vosoghifar, H. R., and Jazayeri, P. (2011). Evaluation of optimum performance of lateral intakes. World Academy of Science, Engineering and Technology, 5(8), 301-305.

[6] [6] Tarek Sayed (2019). An experimental study of branching flow in open channels. Limnol. Rev. 19 (2): 93-101.

[7] [7] Al Omari, N. K., and Khaleel, M. S. (2012). Laboratory study of the effect of the branching angle and the branching channel slope on flow. Al-Rafadain Engineering Journal, 20(5), 33-41.

[8] [8] Dehghani, A., Ghodsian, M., Suzuki, K., and Alaghmand, S. (2009). Local scour around lateral intakes in 180 degrees curved channel. In advances in water resources and hydraulic engineering (pp. 821-825) Springer Berlin Heidelberg.

[9] [9] Keshavarzi, A., and Habibi, L. (2005). Optimizing water intake angle by flow separation analysis. Irrigation and Drainage, 54(5), 543-552. doi:10.1002/ird.207

[10][10] Ramamurthy, A., Qu, J., and Vo, D. (2007). Numerical and experimental study of dividing open channel flows. Journal of Hydraulic Engineering, 133(10), 1135-1144

[11][11] Herrero C. A., (2013). Experimental and theoretical analysis of flow and sediment transport in 90degree fluvial diversions. (Ph. D dissertation).

[12][12] Bagheri, S., and Heidarpour, M. (2012). Characteristics of flow over rectangular sharp-crested side weirs. Journal of Irrigation and Drainage Engineering, 138(6), 541-547.

[13][13] Shamloo, H., and Pirzadeh, B. (2007a). Investigation of characteristics of separation zones in T-junctions. Proceedings of the 12th WSEAS International Conference on APPLIED MATHEMATICS", Cairo, Egypt, Desember29-31, 189-193.

[14][14] Shamloo, H., and Pirzadeh, B. (2007b). Numerical investigation of velocity field in dividing open channel flow. Proceedings of the 12th WSEAS International Conference on APPLIED MATHEMATICS", Cairo, Egypt, Desember29-31, 194-198.

[15][15] Ramamurthy, A., and Satish, M. (1988). Division of flow in short open channel branches. Journal of Hydraulic Engineering, 114(4), 428-438.
[16][16] Ramamurthy, A., Minh Tran, D., and Carballada, L. (1990) Dividing flow in open channels. Journal of Hydraulic Engineering, 116(3), 449-455.

[17][17] Hsu, C., Tang, C., Lee, W., and Shieh, M. (2002). Subcritical $90^{\circ}$ equal-width open-channel dividing flow. Journal of Hydraulic Engineering, 128(7), 716-720.

[18][18] Neary, V., and Odgaard, A. (1993). Three-Dimensional flow structure at Open-Channel diversions. Journal of Hydraulic Engineering, 119(11), 1223-1230.

[19][19] Li, C., and Zeng, C. (2009). 3D numerical modelling of flow divisions at open channel junctions with or without vegetation. Advances in Water Resources, 32(1), 49-60.

[20][20] Khaleel, M. S, Taha, K. Y., and Alomari, N. K. (2015). Effect of Main Channel Roughness on the Branching Flow. Al-Rafadain Engineering Journal, 23(1), 51-61.

\section{Title Arabic:}

$$
\text { تأثير خثونة قاع القناة الرئيسية علي التصرف في القناة الفرعية }
$$

\section{Arabic Abstract:}

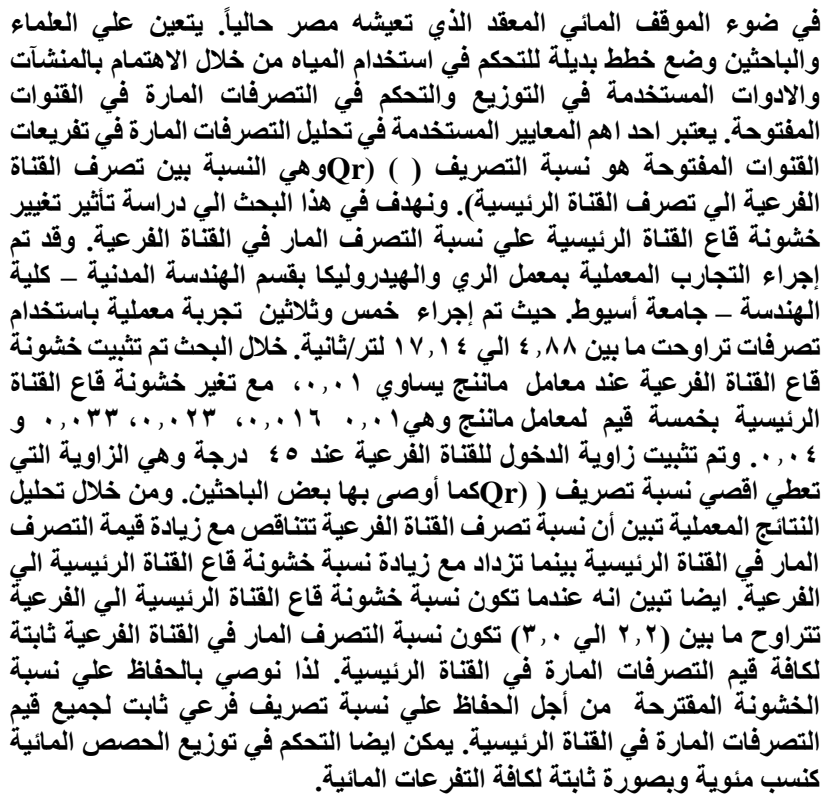

